many useful illustrations and not too many 'commercial' pictures and line diagrams. A mine of information? Yes, but also a very interesting and stimulating one for all who have the opportunity to quarry therein. Unquestionably this is one of the best books available in this area. I only wish the

\section{Condensed state helium}

The Physics of Liquid and Solid Helium. Part II. Edited by K. H. Bennemann and J. B. Ketterson. Pp.750. (Wiley: New York and Chichester, UK, 1978.) $£ 45.85$.

THE helium atom probably comes closer than any other to the miniature "billiard ball" of classical kinetic theory. One might expect, therefore, that the physics of liquid and solid helium would be exceptionally simple and even-perhaps, rather dull. The reality is far otherwise, thanks mainly to the profound influence of quantum statistics: a collection of these small, rigid spheres displays a quite unparalleled richness and variety of physical phenomena some of which, such as bulk superfluidity, are unique on earth (although they may, perhaps, also manifest themselves within the nucleonic fluids in the interiors of dense stars).

In the 1960 s it was still possible (just) for a single author to prepare a research monograph providing a reasonable coverage of virtually everything that was known about condensed state helium; but, such has been the expansion of knowledge over the intervening years, this is hardly the case any more in the late 1970s. The admirable texts by Wilks (The Properties of Liquid and Solid Helium; Clarendon: Oxford, 1967) and by Keller (Helium-3 and Helium-4; Plenum: New York, 1969) are thus almost certainly the last of their kind. In presenting the fruits of more recent researches, Bennemann and Ketterson have very sensibly chosen to solictit individual chapters from a selection of experts. Although inevitably lacking the coherence, internal selfconsistency and the helpful crossreferencing associated with a singleauthor monograph, the result is a collection of weighty, authoritative and, on the whole, very interesting review articles.

This second volume is strongly biassed towards helium-3 which is, of course, entirely appropriate given the enormous progress made towards elucidating the properties of its super- publishers had had more faith in its success to reduce the price and thus allow a greater audience of students to expose themselves to having their own copy.

T. S. West

$\bar{T} . S$. West is Director of the Macaulay Institute for Soil Research, Aberdeen, UK.

fluid phases following their discovery in 1972. The first three chapters are tough going, relatively speaking, being mostly devoted to a formal development of the theory: Baym and Pethick deal with the theory of normal (nonsuperfluid) liquid ${ }^{3} \mathrm{He}$ and with ${ }^{3} \mathrm{He}-{ }^{4} \mathrm{He}$ solutions; Anderson and Brinkman cover anisotropic superfluidity in liquid ${ }^{3} \mathrm{He}$. Most graduate students would be well advised to start instead on chapter 4 , by Lee and Richardson. Running to more than 200 pages their contribution is virtually a book in its own right. They explain and discuss in considerable detail almost all the experimental work carried out on superfluid ${ }^{3} \mathrm{He}$ up to a cut-off date in mid 1976, conveyting in an admirable way the relationship between the experiments

\section{Bile salts}

The Biological Importance of Bile Salts. By G. A. D. Haslewood. Pp.206. (North-Holland: Amsterdam, New York and Oxford, 1978.) \$55.75; Dfl. 125.

THE interest in bile salts of the author of this useful publication is of very long standing. However, the author points out in the preface that this volume does not represent a second edition of his earlier publication entitled Bile Salts (1967). As remarked later in the present book, its purpose is to put the reader into the biological picture (physiological, biochemical, taxonomic and medical) regarding bile salts.

How can such a slim volume, with only some 200 pages, expect to achieve this aim? Professor Haslewood has succeeded by being selective. The book does not, for example, deal in any detail with the chemistry of bile salts, and the references (up to 1978) are described as a personal choice selected partly for their general interest. The author considers that, in these times of computer storage and retrieval, completeness seems an unnecessary aim and may make reading difficult and dull. Several chapters therefore commence by providing appropriate documentation to comprehensive earlier sources for background information. and the growing theoretical structure.

The remaining chapters are devoted to articles on three very disparate topics: by Dash and Schick on twodimensional helium, concentrating, in particular, on the recent fascinating investigations of helium adsorbed on grafoil substrates; by Brewer on multilayer helium films in restricted geometries; and by Price on neutron scattering from helium. Each of these is excellent in its own way and, like the articles on ${ }^{3} \mathrm{He}$, they should be a real help both to people entering, as well as to those already working in, the field in question.

The quality of production is high, as indeed it should be, considering the price. Very few private individuals will be able to afford personal copies; but the book provides a substantial and probably lasting contribution to the literature on condensed state helium and, as such, it will obviously be an essential purchase for libraries.

P. V. E. McClintock

P. V. E. McClintock is Senior Lecturer in the Department of Physics at the University of Lancaster, UK.

The monograph has been produced to a high standard, with few printer's errors. It has five main chapters, of which the longest reflects the author's interest in the distribution of bile salts in the animal kingdom-for example, "Thus, crocodilian bile is quite primitive and generalised: a halt on the main route of bile salt evolution". The other chapters deal with the nature and function of bile, chemistry and methods of separation and analysis of bile salts, their biosynthesis and artefacts of the enterohepatic circulation, and their medical importance.

An Appendix contains 16 pages of tabulated data consistent with the intention that, throughout their studies, the author and his colleagues have tried to publish records of all bile salts discovered. The possible medical relevance of such compilations is shown by the observation ( 189 ) that the tree "shrew" has advantages as a laboratory animal since this primate has bile much mone like man than other small laboratory species, and can easily be induced to form cholesterol gallstones.

This monograph will thus be useful to many workers concerned with a number of different aspects of bile salts in biology and medicine.

J. A. Lucy

J. A. Lucy is Professor of Biochemistry and Head of the Department of Biochemistry and Chemistry at the Royal Free Hospital School of Medicine, London, UK. 